\title{
The tetrapod fauna of the upper Permian Naobaogou Formation of China: 3. Jiufengia jiai gen. et sp. nov., a large akidnognathid therocephalian
}

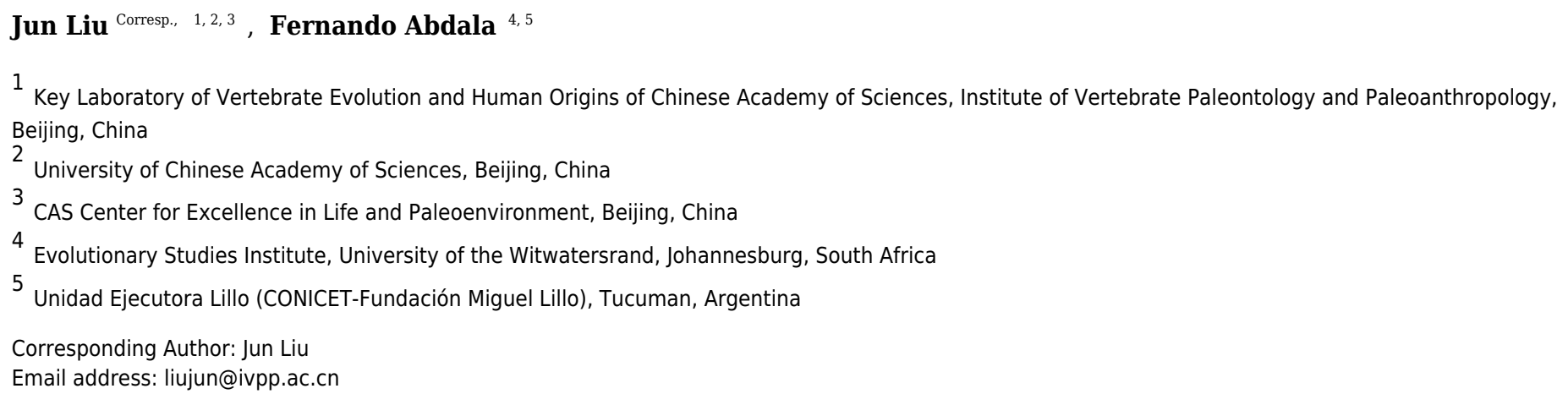

Recent field trips to the Member III of the Naobaogou Formation, Nei Mongol, China resulted in new fossils discoveries increasing our knowledge of the late Permian continental fauna from China. We present here a new large therocephalian, Jiufengia jiai gen. et sp. nov., represented by a partial skull with mandibles and part of the postcranial skeleton. This is the second therocephalian recovered from the Naobaogou faunal association and, in turn, the second akidnognathid from this unit and from China. The new taxon shows clear differences from Shiguaignathus wangi, the akidnogathid previously reported from the Naobaogou Formation: the presence of four upper postcanines, of a large suborbital vacuity, and the flat ventral surface of vomer, lacking ventromedian crest. Updating a previous phylogeny of therocephalians, we recover the new species as a basal member of Akidnognathidae, after a basal polytomy including the other two Laurasian akidnognathids, Shiguaignathus and Annatherapsidus, adding support to the hypothesis that this group originated in Laurasia. 


\section{The tetrapod fauna of the upper Permian Naobaogou Formation of China:}

2 3. Jiufengia jiai gen. et sp. nov., a large akidnognathid therocephalian

3

4 Jun Liu ${ }^{1,2,3}$ Fernando Abdala ${ }^{4,5}$

5

61 Key Laboratory of Vertebrate Evolution and Human Origins of Chinese Academy of Sciences,

7 Institute of Vertebrate Paleontology and Paleoanthropology, Chinese Academy of Sciences

8 Beijing, China

92 CAS Center for Excellence in Life and Paleoenvironment Beijing, China

103 University of Chinese Academy of Sciences Beijing, China

114 Unidad Ejecutora Lillo (Conicet-Fundación Miguel Lillo), Tucumán, Argentina

125 Evolutionary Studies Institute, University of the Witwatersrand, Johannesburg, South Africa

13

14 Corresponding Author:

15 Jun Liu

16 No. 142 Xizhimenwai Street, Beijing, 100044, China

17 Email address: liujun@ivpp.ac.cn 


\section{ABSTRACT}

Recent field trips to the Member III of the Naobaogou Formation, Nei Mongol, China resulted in new fossils discoveries increasing our knowledge of the late Permian continental fauna from China. We present here a new large therocephalian, Jiufengia jiai gen. et sp. nov., represented by a partial skull with mandibles and part of the postcranial skeleton. This is the second therocephalian recovered from the Naobaogou faunal association and, in turn, the second akidnognathid from this unit and from China. The new taxon shows clear differences from Shiguaignathus wangi, the akidnogathid previously reported from the Naobaogou Formation: the presence of four upper postcanines, of a large suborbital vacuity, and the flat ventral surface of vomer, lacking ventromedian crest. Updating a previous phylogeny of therocephalians, we recover the new species as a basal member of Akidnognathidae, after a basal polytomy including the other two Laurasian akidnognathids, Shiguaignathus and Annatherapsidus, adding support to the hypothesis that this group originated in Laurasia.

\section{INTRODUCTION}

The record of Chinese terrestrial strata of Permian age is well documented and has produced a good representation of amniotes ( $\mathrm{Li} \& \mathrm{Liu} 2015$; Li et al. 2008). In recent years, a meticulous collective effort in Permian localities resulted in a remarkable expansion of the knowledge of the faunal members of terrestrial ecosystems (Li \& Liu 2013; Liu 2013; Liu \& Bever 2015; Liu \& Li 2013; Liu et al. 2014; Reisz et al. 2011; Xu et al. 2015), and has also been successful in the record for the first time of therocephalians in the Chinese Permian (Liu \& Abdala 2017a; Liu \& Abdala 2017b). The Naobaogou Permian fauna was recently expanded by the presence of Shiguaignathus wangi, represented by a medium-sized and well-preserved snout, identified as the first Permian akidnognathid therocephalian from China (Liu \& Abdala 2017a), and of the pareiasaur Elginia wuyongae, which implied a significant expansion of the distribution of this parareptile (Liu \& Bever 2018).

Therocephalians constitute a heterogeneous group in the Permian, represented by three speciose lineages. One of these is Akidnognathidae, first erected as Akidognathinae by Nopcsa (1928) to include Akidnognathus parvus Haughton 1918, represented by a small skull with a relatively broad snout from the Cistecephalus Assemblage Zone of South Africa, originally included in Scaloposauridae (Haughton 1918). Later, Akidnognathidae was proposed to include Akidnognathus, Cerdosuchoides, Scylacosaurus and Ictidosaurus (Haughton \& Brink 1954). The latter two genera are currently included in Scylacosauridae, a family including the basal and oldest therocephalians (van den Heever 1994, Abdala et al., 2008). The Family Euchambersidae (Boonstra 1934; Haughton \& Brink 1954) was proposed to include the bizarre skull of Euchambersia mirabilis Broom 1931, although the spelling was later corrected as Euchambersiidae (von Huene 1940). Several other taxa considered now as akidnognathids were previously included in Moschorhinidae, Annatherapsididae (Mendrez 1974a; Mendrez 1975) and Euchambersiidae (Hopson \& Barghusen 1986). Nowadays Akidnognathidae, in a phylogenetic context, include the South African late Permian Akidnognathus, Promoschorhynchus, Euchambersia and Cerdosuchoides, the Permo-Triassic Moschorhinus, the Early Triassic 
59 Olivierosuchus; the Russian late Permian Annatherapsidus and the recently described Chinese 60 Shiguaignathus (Huttenlocker \& Smith 2017; Liu \& Abdala 2017a).

61 Here we report the second akidnognathid from China and only the third for Laurasia, which 62 clearly indicates that this predominantly Gondwanan lineage of therocephalian also has a 63 reasonable representation in the Permian from Laurasia. In fact, two of the three therocephalian

Nomenclatural acts - The electronic version of this article in Portable Document Format (PDF) will represent a published work according to the International Commission on Zoological Nomenclature (ICZN), and hence the new names contained in the electronic version are effectively published under that Code from the electronic edition alone. This published work and the nomenclatural acts it contains have been registered in ZooBank, the online registration system for the ICZN. The ZooBank LSIDs (Life Science Identifiers) can be resolved and the associated information viewed through any standard web browser by appending the LSID to the prefix http://zoobank.org/. The LSID for this publication is: urn:lsid:zoobank.org:act: EBA64D9C-595D-4AF7-B1CB-3B062623C4D2. The online version of this work is archived and available from the following digital repositories: PeerJ, PubMed Central and CLOCKSS.

\section{SYSTEMATIC PALEONTOLOGY}

THERAPSIDA Broom, 1905

THEROCEPHALIA Broom, 1903

EUTHEROCEPHALIA Hopson and Barghusen, 1986

AKIDNOGNATHIDAE Nopcsa, 1928

Jiufengia jiai gen. et. sp. nov.

Etymology - 'Jiufeng", refers to the name of the mountain where the fossil was collected; 'Jia' after Jia Zhen-Yan, the technician who discovered the specimen.

Holotype-IVPP V 23877, a skull with mandibles, incomplete right pectoral girdle, and incomplete right forelimb.

Type Locality and Horizon-Locality DQS 72, near Wuliangshitai, Gongshanwan, Tumd Right Banner, Nei Mongolia, China; base of Member III, Naobaogou Formation.

Diagnosis - A large akidnognathid with the following autapomorphies: snout (preorbital region) longer than half of skull length; anteroposteriorly short temporal region with orbit being slightly larger than the temporal opening; jugal anterior process extends nearly to the level of the anterior margin of the lacrimal; ventral surface of vomer flat, lacking ventromedian crest; pterygoid transverse flange anterior to centre of orbit; prootic without central process; anteroventral process of the squamosal forms the bar anterior to the pterygo-paroccipital foramen; jugal tall below the orbit, intermediate between the condition of Moschorhinus and remaining akidnognathids.

\section{DESCRIPTION}

The specimen consists of the skull, mandibles, left scapula, right coracoid, partial right humerus, proximal portion of the right radius and partial right manus. The skull is slightly crushed along 
100

101

102

103

104

105

106

107

108

109

110

111

112

113

114

115

116

117

118

119

120

121

122

123

124

125

126

127

128

129

130

131

132

133

134

135

136

137

138

139

140

the middle part of the dorsal surface, and some bones on its right lateral side and dorsal surfaces are eroded (Figs. 1-3). The skull occludes with the mandibles. A list of standard cranial measurements is provided in Table 1.

\section{Skull roof}

A prominent feature is the long snout, which represents more than half $(58 \%)$ the length of the skull (Fig. 1; see Table 1). The skull has a triangular outline in dorsal view, being slightly constricted behind the canine and wider posteriorly. The general morphology resembles that of Annatherapsidus, but the latter does not show constriction behind the canine (Ivakhnenko, 2011: fig. 22a).

The laterally wide premaxilla features an eroded anterior tip and ascending processes. The anterior surface of the right side is also eroded exposing the roots of some incisors (Fig. 2). The premaxilla has a narrow exposure on the lateral side, covered by the anterior lamina of the maxilla (Fig. 1). The alveolar margin of the premaxilla upturns anteriorly. The dorsal surface of the bone forms the ventral rim of the external nares with overlapping septomaxilla, only preserved on the left side. On the palate, the premaxilla meets the vomer with a short, trapezoid, posteriorly-directed vomerine process (Fig. 3).

There are five upper incisors (Fig. 2). Although the lateral surfaces of the alveoli are eroded, the crowns of the left five incisors are still preserved, whereas the crowns have nearly vanished on the right side. The incisors are narrow, sharp conical, slightly curved lingually and somewhat anteriorly directed from alveoli. In lateral view, the alveolar margin is nearly straight. The anterior four incisors are similar in the crown height $(\mathrm{ca} .2 \mathrm{~cm})$, the fourth has the largest diameter, and the fifth is smaller.

The maxillary dorsal margin is incomplete, and most of the suture with the nasal is untraceable (Fig. 1). The maxilla contacts the prefrontal posterodorsally and the lacrimal and jugal posteriorly. It has a triangular posterior process which contacts with the also triangular anterior process of the jugal. The maxilla is very high (height is close to $40 \%$ of the bone length) and long, forming the majority of the lateral region of the snout. It extends anteriorly to the position of the fourth incisor and contacts both the septomaxilla and premaxilla. Its height increases posteriorly, and the margins of the maxillae from both sides almost meet along the midline on the dorsal surface (Fig. 4), suggesting the presence of a very narrow nasal at that point of the skull. The maxilla also bears numerous longitudinal grooves and pits, but not foramina, on the external surface of the facial plate. In lateral view, the ventral margin of the maxilla is slightly convex and directed anterodorsally in front of the level of the canine, while the posterior part is nearly straight.

In palatal view the maxilla has a broad exposure medial to the canine alveoli, approaching the wide anterior margin of the vomer. The maxillary exposure on the palate is constricted behind the canine, and its alveolar buccal margin is laterally concave. The maxilla houses two precanines, one canine, and four postcanines. The two small precanines are conical; the canine is cylindrical, with a diameter of $10 \mathrm{~mm}$ at the base. The apex of the canine is lost, and the preserved crown has more than $3 \mathrm{~cm}$ in height. The canine extends below the ventral margin of 
141 the lower jaw (Fig. 1). The canine is slightly curved posteriorly, and its crown surface is covered 142 by regular longitudinal striations. A wide diastema is present posterior to the canine. The 143 postcanines are conical, with a massive base and posteriorly curved crown, which is slightly 144 flattened labiolingually. The two more posterior postcanines have bigger crowns than the first 145 two. The third postcanine is more strongly curved posteriorly when compared with the other 146 postcanines.

147 Only the posterior portion of the nasals is preserved, close to the prefrontals. The dorsal surface 148 of the nasal on the left side is relatively well-preserved. The suture between the nasal and the 149 frontal is unclear. If the posterior extension of the nasal is level with the anterior margin of the sagittal crest is observed on the nasal.

Only the left orbit is preserved (Figs. 1, 4). The orbit is rounded in dorsal view, and has a $44 \mathrm{~mm}$ anteroposterior length. The anterior wall of the orbit is formed by the prefrontal and lacrimal; the relatively deep suborbital bar is formed by the jugal, and maxilla only anteriorly; and the moderately slender postorbital arch is formed by the jugal and postorbital. The dorsal roof of the left orbit is incomplete. The lacrimal sutures with the prefrontal dorsally and the jugal ventrally. It is a rectangular bone in lateral view (Fig. 1). The triradiate jugal has a long anterior process, which reaches nearly the level of the anterior margin of the lacrimal. The jugal also extends anteriorly beyond the anterior margin of the orbit in Akidnognathus and Annatherapsidus, but it does not approach the anterior margin of the lacrimal (Ivakhnenko 2011). Posteriorly, it contacts the anterior process of the squamosal approximately midway beneath the temporal fenestra, forming the zygomatic arch.

The prefrontal is roughly triangular in dorsal view (Fig. 4). It contacts medially with the nasal and frontal. The frontal is poorly preserved. The postorbital has a long ventral process that covers the lateral surface of the jugal and partially forms the suborbital bar. The anterodorsal portion of the postorbital is missing, and the posterior process is short, forming the anterior lateral surface of the temporal fenestra, below the parietal crest (Fig. 5).

The temporal fenestra is roughly quadrangular (Figs. 1, 4). It is only slightly longer than the orbit anteroposteriorly.

The parietal is short, forming most of the narrow intertemporal region (Fig. 4). It forms a parietal crest which is more than half of the temporal fenestra length. There is no evidence of the parietal foramen due to poor preservation. The parietal forms the central portion of the lambdoidal crest, which is mostly eroded in the specimen, and also extends ventrally to contact the interparietal on the occiput (Fig. 6).

The squamosal extends medially to contact the parietal and posteriorly the tabular. In occipital view, it reaches the post-temporal fossa and forms its dorsolateral corner(Fig. 6). The squamosal extends ventrally to encase the lateral surface of the paroccipital process of the opisthotic, forming a rudimentary mastoid process (Fig. 3). The posteroventral margin of the squamosal forms a vertical notch to accommodate the quadrate and quadratojugal. Anteromedially, it has a long ventral process which contacts the quadrate process of the pterygoid and the paroccipital process. The squamosal sends an anteroventral process to contact the prootic medially and the 
182

183

184

185

186

187

188

189

190

191

192

193

194

195

196

197

198

199

200

201

202

203

204

205

206

207

208

209

210

211

212

213

214

215

216

217

218

219

220

221

222

epipterygoid anteroventrally (Figs. 4, 5). This process forms the bar anterior to the pterygoparoccipital foramen.

\section{Palate}

The choana is confluent with the fossa for the lower canine, and it extends anteriorly to the level of the last incisor and posteriorly to the level of the third postcanine (Fig. 3). The choana is bordered laterally by the maxilla and palatine, anteriorly by the premaxilla, medially by the vomer, and posteriorly by the vomer and palatine.

The unpaired vomer is wide, anteriorly contacting the vomerine process of the premaxilla. The suture between these bones lies posterior to the level of the anterior margin of the choanae. Its anterior width is greater than half of the vomer length between choanae. The vomer is narrow at the level of the posterior margin of the choana, but it is much wider than in most akidnognathids, with the exception of Moschorhinus (Liu \& Abdala 2017a). The greatest width of the vomer is at the level of the posterior margin of the choanae, and progressively reduces its width posteriorly until it contacts with the pterygoid, which is posterior to the level of the anterior margin of the suborbital vacuity, as in Olivierosuchus parringtoni (Botha-Brink \& Modesto 2011). The posterior plate of the vomer is ventrally concave, lacking a ventromedian crest. In most akidnognathids, the ventromedian crest is developed on both anterior and posterior plates of the vomer, and only on the posterior plate in Olivierosuchus (Botha-Brink \& Modesto 2011; Liu \& Abdala 2017a:fig. 6).

The palatine has a slightly curved medial suture with the vomer. Its lateral suture with the maxilla is almost parallel to the lateral margin of the skull (Fig. 3). The posterolateral process of the palatine extends to the middle of the lateral margin of the suborbital vacuity. The posteromedial side covers the pterygoid. The medial portion of the palatine almost lies on the same plane as the nearly flat lateral portion, and the posterior part of the crista choanalis is a crest on a nearly flat surface. The crista choanalis turns laterally behind the posterior margin of the choanae, and extends to the notch on the anterior margin of the suborbital vacuity. On the lateral portion, the palatine bifurcates in two short anterior processes located lateral and medial to the maxillo-palatine foramen. The maxillo-palatine foramen lies at the level of the anterior margin of the first postcanine.

The suborbital vacuity is large, slightly longer than it is wide (Fig. 3). The vacuities in the specimen have a different size, but the left one seems to be less distorted and closer to the natural size. The vacuity is formed anteriorly by the palatine, medially and posteriorly by the pterygoid, and posterolaterally by the ectopterygoid. On the medial margin of the vacuity the palatine and the pterygoid form two parasagittal crests, which become two tuberosities. Between them, a prominent ventromedial tuber lies anterior to the interpterygoid fossa, similar to the morphology observed in Promoschorhynchus (Mendrez 1974b). The lateral lamina of the pterygoid is poorly developed.

The transverse process extends laterally and terminates in a swollen tuberosity (Fig. 3) as in Annatherapsidus (Ivakhnenko 2011), and Oliverosuchus (Botha-Brink \& Modesto 2011). The transverse process is more or less horizontal on the medial side, but it turns nearly vertical 
223 laterally.

224 The ectopterygoid is contacted ventrally and anteriorly by the palatine, and it expands 225 dorsoventrally at the posterior portion. The ectopterygoid forms a fossa on the posterolateral 226 corner of the suborbital vacuity.

227 The interpterygoid fossa is quite small, as in Annatherapsidus (Ivakhnenko 2011). It lies at the 228 base of the transverse processes. The very short edges of the interpterygoid fossa meet to form a 229 posteromedial crest, which connects with the high and sharp parasphenoid keel. The

230

231

232

233

234

235

236

237

238

239

240

241

242

243

244

245

246

247

248

249

250

251

252

253

254

255

256

257

258

259

260

261

262

263 basisphenoid process of the pterygoid extends posteriorly to form the lateral margin of the external opening of the internal carotid canal, together with the parabasisphenoid. The lamina between the quadrate process and the basisphenoid process is strongly concave ventrally, bordered laterally by the strong crest of the quadrate process.

The dorsal portion, and possible partial ventral portion, of the right quadrate is preserved. It is an expanded lamina located adjacent to the anterior surface of the squamosal. There is no evidence of the quadratojugal.

\section{Braincase}

The parabasisphenoid features an anterior parasphenoid keel and a wide, deep groove located between the strong spheno-occipital tubercles (Fig. 3). The parabasisphenoid forms the majority of the anterior margin of the fenestra ovalis, while the basioccipital forms the medial margin of the fenestra ovalis.

The posterior portion of the basicranium is incomplete with part of the basioccipital and exoccipitals eroded (Fig. 3). Anteriorly, the basioccipital participates in the formation of the spheno-occipital tubercle; laterally it contacts the opisthotic and posterolaterally it sutures with two exoccipitals, forming the ventral margin of the foramen magnum (Fig. 6).

The exoccipital forms the lateral portion of the occipital condyle and the foramen magnum (Fig. 3). The bone is nearly triangular in occipital view (Fig. 6). Its medial side forms the lateral wall of the foramen magnum, and its ventral side contributes to the roof of the large jugular foramen. The exoccipitals do not meet along the midline.

The occiput is inclined posteriorly (Fig. 3). In the occiput, the supraoccipital is fairly broad. It participates in the formation of the upper margins of the foramen magnum, separating the exoccipitals (Fig. 6). Anteriorly, it is also exposed in the temporal fossa (Fig. 5). From the margin of the foramen magnum, the supraoccipital has a ridge extending dorsolaterally that continues on the tabular, as in Moschorhinus (Durand 1991). The area between these ridges has a deep indentation, mainly on the interparietal and the supraoccipital, for the attachment of the supravertebral cervical muscles. The supraoccipital has a short lateral extension between the opisthotic and the tabular.

The rectangular interparietal is a broad and low bone, with a short median ridge (Fig. 6). The high tabular forms a substantial portion of the lambdoid crest. It extends ventrally to contact the dorsolateral corner of the supraoccipital. Its ventral tip forms part of the dorsal border of the post-temporal fenestra.

The opisthotic consists of a robust paroccipital process, which forms the ventral border of the 
264

265

266

267

268

269

270

271

272

273

274

275

276

277

278

279

280

281

282

283

284

285

286

287

288

289

290

291

292

293

294

295

296

297

298

299

300

301

302

303

304

post-temporal fenestra in the occiput (Fig. 6). A shallow notch divides the mastoid process from the longer quadrate process (ventral flange). The mastoid process has only a rudimentary extension posteriorly, along with the posterior flange of the squamosal. A well-developed posterodorsal process of the opistothic contacts the tabular dorsolaterally and the supraoccipital dorsomedially, and forms half of the dorsal margin of the post-temporal fenestra. The internal process forms a lamina between the fenestra ovalis and the jugular foramen.

The left prootic is well preserved. Its basal area is in contact with the parabasisphenoid posteriorly and it forms the lateral side of the anterior border of the fenestra ovalis (Fig. 3). Its anteroventral and anterodorsal processes are not well exposed, being partially covered by the epipterygoid (Fig. 5). Dorsally, the prootic contacts the supraoccipital, and posterior to the epipterygoid there is a triangular incisure, interpreted as a venous foramen. The long posterodorsal and posteroventral processes contact the squamosal and almost form the entire dorsal and ventral margins of the posttemporal fenestra. There is no central process as described in Promoschorhynchus (Mendrez 1974). In ventral view, the suture between the prootic and the opisthotic runs medially towards the fenestra ovalis and continues on the dorsal border of the fenestra.

Both epipterygoids are preserved, but only the left one is complete (Figs. 3-5). It is a flat, bladelike bone (Fig. 5). It expands dorsally to contact the parietal, and its posterodorsal process contacts the supraoccipital posteriorly. It has a posterior apophysis that is posterior to the posterior foramen, which overlaps the anterodorsal process of the prootic. The basal part expands anteroposteriorly to cover nearly half the length of the quadrate ramus of the pterygoid. The posteroventral process contacts the squamosal, and a foramen [ $\mathrm{f}$ in Fig. 4] is separated from the large cavum epiptericum.

\section{Mandible}

Both mandibles are preserved, but the right one is more complete (Figs. 1, 7). The dentary is long and deep, and the well-developed coronoid process has a straight terminal end. The horizontal ramus is constricted in height behind the canine, and distinctly expands posteriorly to the last postcanine (Fig. 7). A tall unfused symphysis forms a deep anterior chin. It is smoothly convex anteriorly in lateral view, forming an angulation of $110^{\circ}$ with the dentary ventral margin. The dentary lateral surface is convex outwards, lacking any fossa. The dentary angle, anterolateral to the reflected lamina, is rounded and slightly convex.

The dentary contains four incisors, one canine and five or six postcanines. The fourth incisor is smaller and located laterally to the others based on the CT image. Five posteriorly inclined postcanines are counted on the left, and six on the right. However, the first right postcanine could be a replacing canine. The first left postcanine is smaller than the others, whereas the last right postcanine $(4 \mathrm{~mm})$ is less than half the size of the previous teeth.

The splenial is an elongated bone (Fig. 3). Anteriorly, it meets its counterpart and participates in the formation of the lower part of the symphysis. It reaches the highest point below the second postcanine where its dorsal border is close to the upper margin of the dentary, and decreases in height from there until the level of the last postcanine, from where it extends posteriorly as a 
305

306

307

308

309

310

311

312

313

314

315

316

317

318

319

320

321

322

323

324

325

326

327

328

329

330

331

332

333

334

335

336

337

338

339

340

341

342

343

344

345

slender rod. It contacts the angular posteriorly behind the level of the transverse process, but the suture is not clearly visible. The ventral margin of the splenial is nearly confluent with that of the dentary near the symphysis, but it gradually rises posteriorly.

The postdentary fossa is elongated and formed by the surangular, prearticular, and angular (Fig. 7). The surangular is a narrow strip, having a concave ventral margin as the dorsal border of the mandibular fenestra. The mandibular fenestra is exposed laterally posterior to the dentary. The angular forms the ventral border of the fenestra on the lateral side. The angular reflected lamina has a wide ' $U$ '-shaped notch posteriorly, which is more posteriorly than dorsally directed. The lateral surface of the reflected lamina is ornamented with ridges, grooves and corrugations. The prearticular is a narrow, splint-like bone, which extends anteriorly to the level of the transverse process (Fig. 3). It forms the ventral margin of the mandibular fenestra on the medial side. A triangular coronoid forms the anterior margin of the mandibular fenestra on the medial side. The articular is partially preserved and has no features to mention.

\section{Postcranial skeleton}

Some disarticulated postcranial bones were preserved with the skull. The following are the only identifiable elements.

Pectoral girdle. Only part of the ventral portion of the right scapula (Fig. 8A) was preserved. The right coracoid is complete, and a small piece of procoracoid is fused to it (Fig. 8B, C). The glenoid fossa seems to be formed by only the coracoid and scapula. The coracoid is expanded ventrally and curved inwards towards the midline. The tuberosity for the coracoid head of the triceps lies posteroventral to the glenoid and far from it, as in Promoschorhynchus (Huttenlocker et al. 2011) and other therocephalians (Kemp 1986). A small fossa lies on the posterodorsal side of the medial surface of the coracoid, just below the articular surface. Some longitudinal striations are observed anterior to this fossa and might be for the attachment of the muscle subcoracoideus.

Forelimb. The right humerus lost most of its proximal and distal ends (Fig. 8D, E). The proximal half of the bone curves dorsally relative to the distal half. The proximal half is broad, with a smoothly concave ventral surface limited anteriorly by the deltopectoral crest and posteriorly by a ridge. The middle diaphysis is short and approximately circular in cross section, beyond which the bone expands to form the wide distal region. A large entepicondylar foramen lies in the posterior face and opens anteriorly into a deep trough on the ventral surface.

The proximal portions of the right ulna and radius are preserved. The ulna has no olecranon process, and the proximal side is rough (Fig. 8F, G). In anterior view, the proximal articular facet is lateromedially expanded. Ventral to the proximal end is a fossa for the origin of the extensor musculature (Fig. 8F). The radius has a thin shaft and expanded end. The proximal articulating facet is concave (Fig. 8H, I). A sharp ridge extends on the posterior side of the bone, below the facet for articulation to the ulna.

Elements of four digits of the right manus, identified as digits I-IV, are preserved together (Fig. 9). Their shape is similar to that of Oliverosuchus (Botha-Brink \& Modesto 2011). Distal carpals 1 and 2 are preserved. The medial surface of distal carpal 1 is strongly concave and the distal is 
346

347

348

349

350

351

352

353

354

355

356

357

358

359

360

361

362

363

364

365

366

367

368

369

370

371

372

373

374

375

376

377

378

379

380

381

382

383

384

385

386

articulated with the metacarpal I. A bone in contact with metacarpal II is interpreted as an out of place distal carpal 2. The bone is relatively large and transversely expanded on one side. Metacarpals I-IV are nearly complete, measuring 7, 22, 29 and $30 \mathrm{~mm}$ respectively. The rectangular, wider than longer, metacarpal 1 is remarkably short and squat, differing from the quadrangular element of Olivierosuchus (Botha-Brink and Modesto, 2011: text-fig. 7). The other three metacarpals are long with expanded ends, and with similar length as the III and the IV, which are longer than the II. A similar pattern of metacarpal lengths is represented in Olivierosuchus (Fontanarrosa et al, in press: fig. 3B). The diaphysis of metacarpal II is remarkably wider than that of metacarpals III and IV (Fig. 9B). The phalanges preserved for each digit are 2-2-1-3, including three disarticulated phalanges from digit IV (Fig. 9C, D). The terminal (ungual) phalange is narrow, pointed and claw-like, while the others are short, broad and squat.

\section{DISCUSSION}

The fossil record of therocephalians has been historically poorly represented in the extensive exposures of the terrestrial Chinese Permian. However, the recent discovery of two new, definitely late Permian therocephalians (Liu and Abdala, 2017a, 2017b) is challenging this situation. The akidnognathid Shiguaignathus wangi, was the first therocephalian reported for the faunal association of the Naobaogou Formation. IVPP V 23877, here described as Jiufengia jiai, is the second therocephalian and, in turn, the second akidnognathid of the Naobaogou assemblage according to the following features: a septomaxilla well exposed outside of the external naris, broadly overlapping the premaxilla anteriorly; a very expanded vomer, broadly overlapping the vomerine process of the premaxilla; and contribution of the premaxilla and maxilla to a fossa for the lower canine on the palatal surface.

Jiufengia jiai is different from the smaller Shiguaignathus wangi from the same horizon by the presence of four upper postcanines, presence of a large suborbital vacuity, and ventral surface of vomer flat, lacking a ventromedian crest.

The dental formula of Jiufengia is I5:pC2:C1:Pc4/i4:c1:pc5. Only Moschorhinus and Olivierosuchus (with three; Durand 1991; Botha-Brink \& Modesto 2011); and Euchambersia (with none; Benoit 2016) have fewer postcanines than Jiufengia. Remaining akidnognathids have from five (e.g., Promoschorhynchus) to a maximum of eight recorded in the other Chinese Permian akidnognathid, Shiguaignathus (Liu and Abdala 2017b). Jiufengia can also be differentiated from other akidnognathids by the long snout which is more than half the skull length, the transverse process is anterior to the orbit, the ventral surface of the vomer is flat along the middle line, lacking a ventromedian crest, and the anterior process of the jugal is nearly level with the anterior margin of the lacrimal. All these characters show that this specimen represents a new species within Akidnognathidae.

The suborbital vacuity of Jiufengia jiai is more similar to Annatherapsidus than other taxa in its large size, anterioposterior length greater than the width, long and relatively straight lateral margin which is more anteriorly than medially directed, and the posterior margin nearly laterally directed. 
387 To reconstruct the phylogenetic position of Jiufengia jiai, we coded it in our previous matrix 388 (Liu \& Abdala 2017a) and included as a terminal the recently described Russian therocephalian 389 Gorynychus (Kammerer \& Masyutin 2018). The matrix was analyzed with TNT 1.5 (Goloboff \& 390 Catalano 2016), as in Liu \& Abdala (2017a): the search for most parsimonious trees (mpt) 391 consisted of 10 random addition sequences and TBR, saving 10 trees per replication, and a 392 second search using the trees from RAM as a starting point and implementing TBR on those 393 trees. Seventeen multistate characters were considered as additives. The search resulted in 7560

394 mpt of 384 steps in which most of the major groups of Therocephalia are recovered as monophyletic (Fig. 10). The result is nearly identical to our previous analysis (compare the consensus tree in figure 10 with the right one in figure 7 of Liu \& Abdala, 2017a). The only differences to report are in the placement of the two new terminals added in the current study. Jiufengia is recovered as a basal akidnognathid, following a politomy at the base of this clade that includes the other two Laurasian akidnognathids Shiguaignathus and Annatherapsidus (Fig. 10). Apart from the Laurasian most basal records of Akidnognathidae, the current evidence shows medium-to-large sized Permian akidnognathids in Laurasia. Of the four late Permian akidnognathids in the Karoo Basin, only Moschorhinus at the end of the Permian shows a large size (maximum skull length $262 \mathrm{~mm}$; Huttenlocker and Botha-Brink, 2013), with remaining taxa ranging between 107 and $\sim 135 \mathrm{~mm}$ in skull length (Table 2). The youngest record of akidnognathid in the Karoo, represented by Olivierosuchus is the smaller representative of the lineage. In contrast, two of the three Laurasian akidnognathids show large sizes (above $200 \mathrm{~mm}$, Table 2), and only Shiguaignathus is a medium-sized animal.

Although the current matrix is only different from that of Kammerer \& Masyutin (2018) in a few characters, the result is quite different regarding the placement of the Russian Gorynychus and Perplexisaurus. In our analysis Gorynychus is one of the basalmost therocephalians, recovered as a sister taxon of Lycosuchus (altough only in the majority consensus tree; Fig. 10). Two characters produce this monophyly: a deep suborbital bar and five or less upper postcanines in adults. Perplexisaurus is recovered as a basal member of the recently defined clade Chthonosauridae (Huttenlocker \& Sidor, 2016). This group has only one synapomorphy: the parietal crest in adults extends forward to include parietal foramen. However the score of this character is unknownin Ichibengops, therefore the only synapomorphy of the group is ambiguous. The differences between our result (that reflect mostly the hypothesis of Huttenlocker and coworkers) and that of Kammerer \& Masyutin (2018) show instability in current hypotheses of therocephalian relationships, which is evident in the support values of monophyletic groups represented in Figure 10. Thus, support values are overall low and are especially poor in basal Therocephalia, Eutherocephalia, Chthonosauridae, basal Akidnognathidae, Whaitsoidea, Whaitsiidae and Lycideopidae.

\section{ACKNOWLEDGEMENTS}

We thank the field team that worked at Daqingshan in 2011 (Jia Zhen-Yan, Li Lu, Li Xing-wen and Liu Yu-feng). Fossil prepared by Fu Hua-lin. Photo by Gao Wei and illustrated by Xu Yong. Reviews by Christian Kammerer and Leandro Gaetano and revision of the English by Lucinda 
Backwell are especially appreciated.

\section{REFERENCES}

Benoit J. 2016. A review of the "venomous therocephalian" hypothesis and how multiple reportrayals of Euchambersia have influenced its success and vice versa. Bulletin de la Société Géologique de France 187:217-224.

Boonstra LD. 1934. A contribution to the morphology of the mammal-like reptiles of the suborder Therocephalia. Annals of the South African Museum 31:215-267.

Botha-Brink J, Modesto SP. 2011. A new skeleton of the therocephalian synapsid Olivierosuchus parringtoni from the Lower Triassic South African Karoo Basin. Palaeontology 54:591-606 10.1111/j.1475-4983.2011.01048.x.

Brink AS. 1986. Illustrated bibliographical catalogue of the Synapsida. Parts 1 and 2. Pretoria: Department of Mineral and Energy Affairs.

Broom R. 1936. On some new genera and species of Karroo fossil reptiles, with notes on some others. Annals of the Transvaal Museum 18:349-386.

Durand JF. 1991. A revised description of the skull of Moschorhinus (Therapsida, Therocephalia). Annals of the South African Museum 99:381-413.

Fontanarrosa, G., Abdala, F., Kümmell, S., Gess, R. in press. The manus of Tetracynodon (Therapsida: Therocephalia) provides strong evidence for survival strategies following the Permo-Triassic extinction event. Journal of Vertebrate Paleontology.

Goloboff PA, Catalano S. 2016. TNT, version 1.5, with a full implementation of phylogenetic morphometrics. Cladistics 32:221-238 doi: 10.1111/cla. 12160.

Haughton SH. 1918. Investigations in South African Reptiles and Amphibians: 11. Some New Carnivorous Therapsida, with Notes upon the Brain_case in Certain Species. Annals of the South African Museum 12:175-216.

Haughton SH, Brink AS. 1954. A bibliographic list of the Reptilia from the Karoo beds of Africa. Palaeontologia Africana 2:1-187.

Hopson JA, Barghusen HR. 1986. An analysis of therapsid relationships. In: Hotton N, III, MacLean PD, Roth JJ, and Roth EC, eds. The Ecology and Biology of Mammal-like Reptiles. Washington D.C.: Smithsonian Institution Press, 83-106.

Huttenlocker AK, Sidor CA, Smith RMH. 2011. A new specimen of Promoschorhynchus (Therapsida: Therocephalia: Akidnognathidae) from the Lower Triassic of South Africa and its implications for theriodont survivorship across the Permo-Triassic boundary. Journal of Vertebrate Paleontology 31:405-421 10.1080/02724634.2011.546720.

Huttenlocker AK, Smith RMH. 2017. New whaitsioids (Therapsida: Therocephalia) from the Teekloof Formation of South Africa and therocephalian diversity during the endGuadalupian extinction. PeerJ 5:e3868 10.7717/peerj.3868.

Ivakhnenko MF. 2011. Permian and Triassic Therocephals (Eutherapsida) of Eastern Europe. Paleontological Journal 45:981-1144 10.1134/s0031030111090012. 
469 Kammerer CF, Masyutin V. 2018. A new therocephalian (Gorynychus masyutinae gen. et sp.

470 nov.) from the Permian Kotelnich locality, Kirov Region, Russia. PeerJ 6:e4933 10.7717/peerj.4933.

Kemp TS. 1986. The skeleton of a baurioid therocephalian therapsid from the Lower Triassic (Lystrosaurus Zone) of South Africa. Journal of Vertebrate Paleontology 6:215-232.

Li J-L, Liu J. 2015. Basal Synapsids. In: Qiu Z-X, editor. Palaeovertebrate Sinica. Beijing: Science Press. p 105.

Li J-L, Wu X-C, Zhang F-C. 2008. The Chinese Fossil Reptiles and Their Kin (second edition). Beijing: Science Press. p 473.

Li X-W, Liu J. 2013. New specimens of pareiasaurs from the Upper Permian Sunjiagou Formation of Liulin, Shanxi and their indication for the taxonomy of Chinese pareiasaurs. Vertebrata Palasiatica 51:199-204.

Liu J. 2013. Osteology, ontogeny and phylogenetic position of Sinophoneus yumenensis (Therapsida, Dinocephalia) from Dashankou Fauna, middle Permian of China. Journal of Vertebrate Paleontology 33:1394-1407.

Liu J, Abdala F. 2017a. The tetrapod fauna of the upper Permian Naobaogou Formation of China: 1. Shiguaignathus wangi gen. et sp. nov., the first akidnognathid therocephalian from China. PeerJ 5:e4150 10.7717/peerj.4150.

Liu J, Abdala F. 2017b. Therocephalian (Therapsida) and chroniosuchian (Reptiliomorpha) from the Permo-Triassic transitional Guodikeng Formation of the Dalongkou Section, Jimusar, Xinjiang, China. Vertebrata Palasiatica 55:24-40.

Liu J, Bever GS. 2015. The last diadectomorph sheds light on Late Palaeozoic tetrapod biogeography. Biology Letters 11:2015.0100 10.1098/rsbl.2015.0100.

Liu J, Bever Gabriel S. 2018. The tetrapod fauna of the upper Permian Naobaogou Formation of China: a new species of Elginia (Pareiasauria). Papers in Palaeontology 4 doi: 10.1002/spp2.1105.

Liu J, Li L. 2013. Large tetrapod burrows from the Permian Naobaogou Formation of the Daqingshan area, Nei Mongol, China. Acta Geologica Sinica (English Edition) 87:15011507.

Liu J, Xu L, Jia S-H, Pu H-Y, Liu X-L. 2014. The Jiyuan tetrapod Fauna of the Upper Permian of China-2. Stratigraphy, Taxonomical review, and correlation with other assemblages. Vertebrata Palasiatica 52:328-339.

Mendrez CH. 1974a. Etude du crane d'un jeune specimen de Moschorhinus kitchingi Broom, 1920 (?Tigrisuchus simus Owen, 1876), Therocephalia, Pristerosauria, Moschorhinidae d'Afrique Australe (Remarques sur les Moschorhinidae el les Whaitsiidae). Annals of the South African Museum 64:71-115.

Mendrez CH. 1974b. A new specimen of Promoschorhynchus platyrhinus Brink 1954 (Moschorhinidae) from the Daptocephalus-Zone (Upper Permian) of South Africa. Palaeontologia Africana 17:69-85.

Mendrez CH. 1975. Principales variations du palais chez les thérocéphales Sud-Africains (Pristerosauria et Scaloposauria) au cours du Permien Supérieur et du Trias Inférieur. 
$510 \quad$ Colloque International CNRS 218:379-408.

511 Nopcsa F. 1928. The genera of reptiles. Palaeobiologica 1:163-188.

512 Reisz RR, Liu J, Li J, Müller J. 2011. A new captorhinid reptile, Gansurhinus $513 \quad$ qingtoushanensis, gen. et sp. nov., from the Permian of China. Naturwissenschaften 98:435$514 \quad 441$.

515 van den Heever JA. 1994. The cranial anatomy of the early Therocephalia (Amniota: 516 Therapsida). Annale Universiteit van Stellenbosch 1994:1-59.

517 von Huene F. 1940. Die Saurier der Karroo-, Gondwana- und verwandten Ablagerungen in 518 faunistischer, biologischer und phylogenetischer Hinsicht. Neues Jahrbuch für Geologie und 519 Paläontologie, Abhandlungen 149:1-65.

520 Xu L, Li X-W, Jia S-H, Liu J. 2015. The Jiyuan tetrapod Fauna of the Upper Permian of 521 China-1. New pareiasaur materials and the reestablishment of Honania complicidentata. 523 Acta Palaeontologica Polonica 60:689-700 http://dx.doi.org/10.4202/app .00035.2013. 


\section{Figure 1}

Holotype of Jiufengia jiai (IVPP V 23877) from the Naobaogou Formation of China. Photo (A) and line drawing (B) of the skull in left lateral view.

Abbreviations: F, frontal; J, jugal; L, lacrimal; $M$, maxilla; N, nasal; P, parietal; PF, prefrontal; PM, premaxilla; PO, postorbital; SM, septomaxilla; SQ, squamosal. Photo credit: Wei Gao. Drawing credit: Yong Xu and Jun Liu.

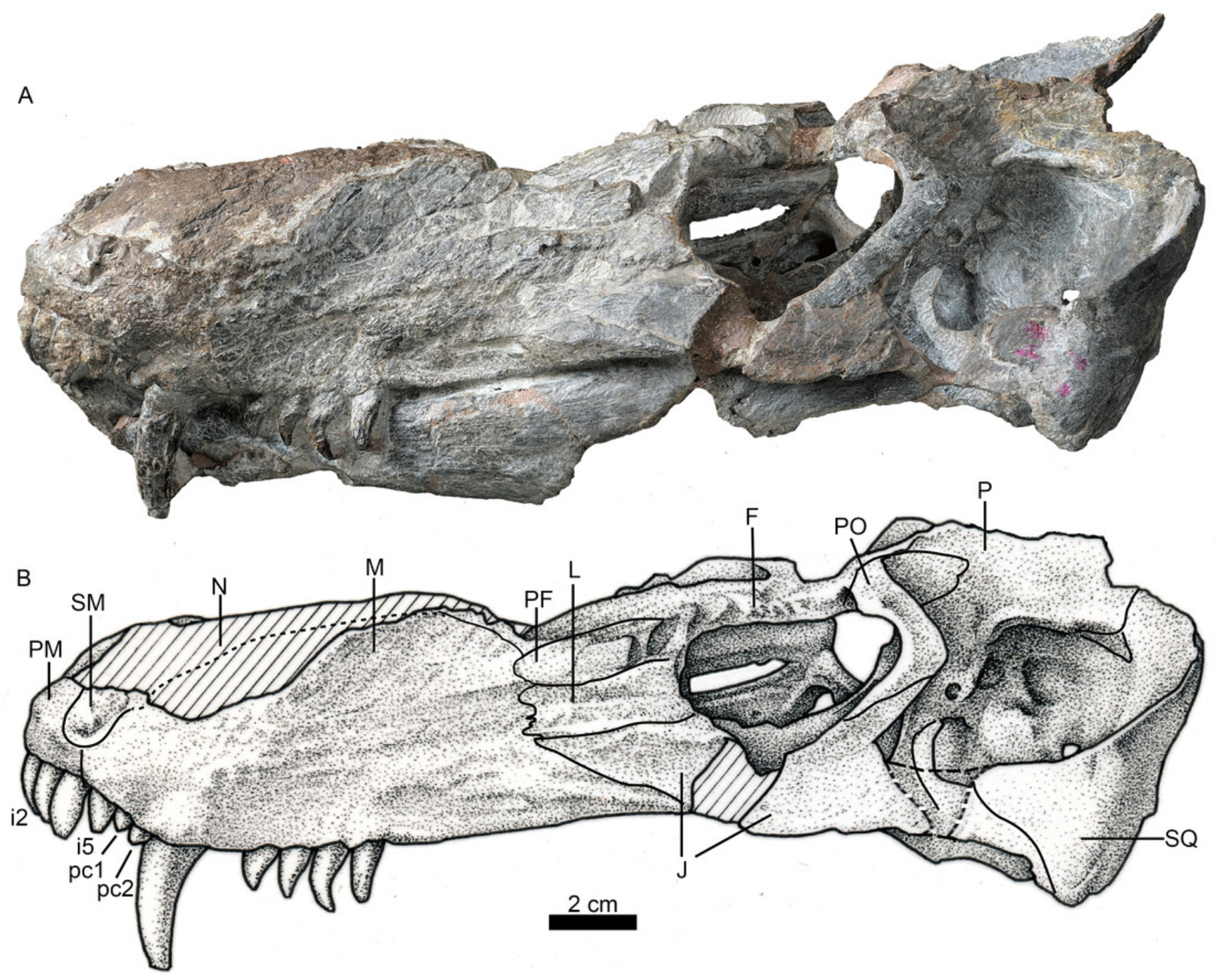




\section{Figure 2}

Holotype of Jiufengia jiai (IVPP V 23877) from the Naobaogou Formation of China. Photo of the skull and mandibles in anterior view.

Abbreviation: I 1 5, incisor 1 5. Photo credit: Wei Gao.

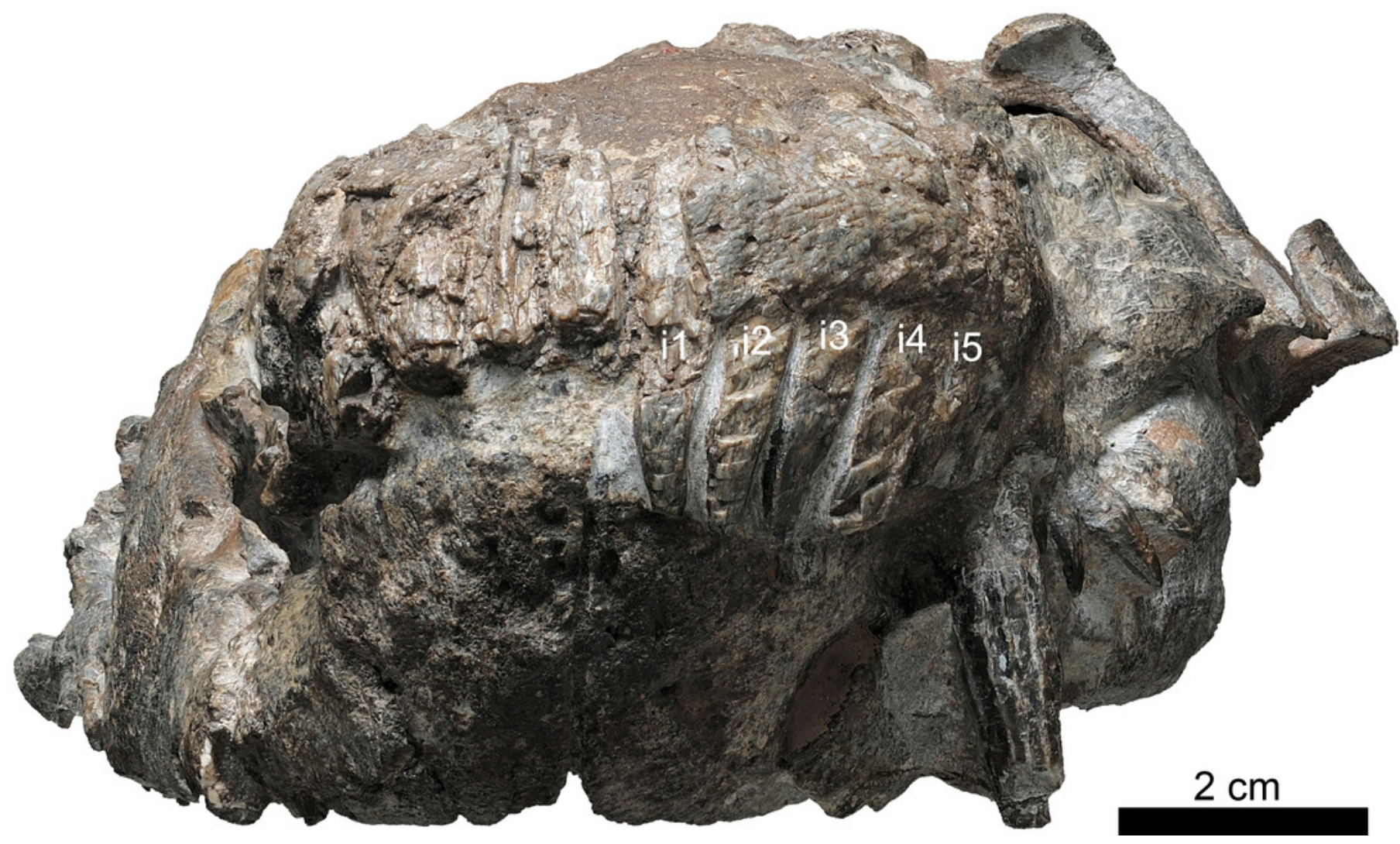




\section{Figure 3}

Holotype of Jiufengia jiai (IVPP V 23877) from the Naobaogou Formation of China. Photo (A) and line drawing (B) of the skull and mandibles in ventral view.

Abbreviations: $A$, angular; $A R$, articular; $\mathrm{BO}$, basioccipital; bspPT, basipterygoid process of the pterygoid; cc, crista choanalis; CR, coronoid; D, dentary; fo, fenestra ovalis; EC, ectopterygoid; EO, exoccipital; eopc, external opening of the parabasal canal; EP, epiptyerygoid; fo, fenestra ovalis; ipf, interpterygoid fossa; ipOP, internal process of the opisthotic; J, jugal; jf, jugular foramen; kPS, parasphenoid keel; M, maxilla; mpf, maxillopalatine foramen; mpOP, mastoid process of the opisthotic; PAR, prearticular; PBS, parabasipterygoid; PL, palatine; PM, premaxilla; PO, postorbital; PpOP, paroccipital process of the opisthotic; PRO, prootic; PT, pterygoid; ptpf, pterygo-paroccipital foramen; Q, quadrate; qpOP, quadrate process of the opisthotic; qrPT, quadrate ramus of the pterygoid; rlA, reflected lamina of the angular; SA, surangular; sot, spheno-occipital tubercle; SP, splenial; SQ, squamosal; tp, transverse process; tub, tuberosity; V, vomer. Photo credit: Wei Gao. Drawing credit: Yong Xu and Jun Liu. 
A

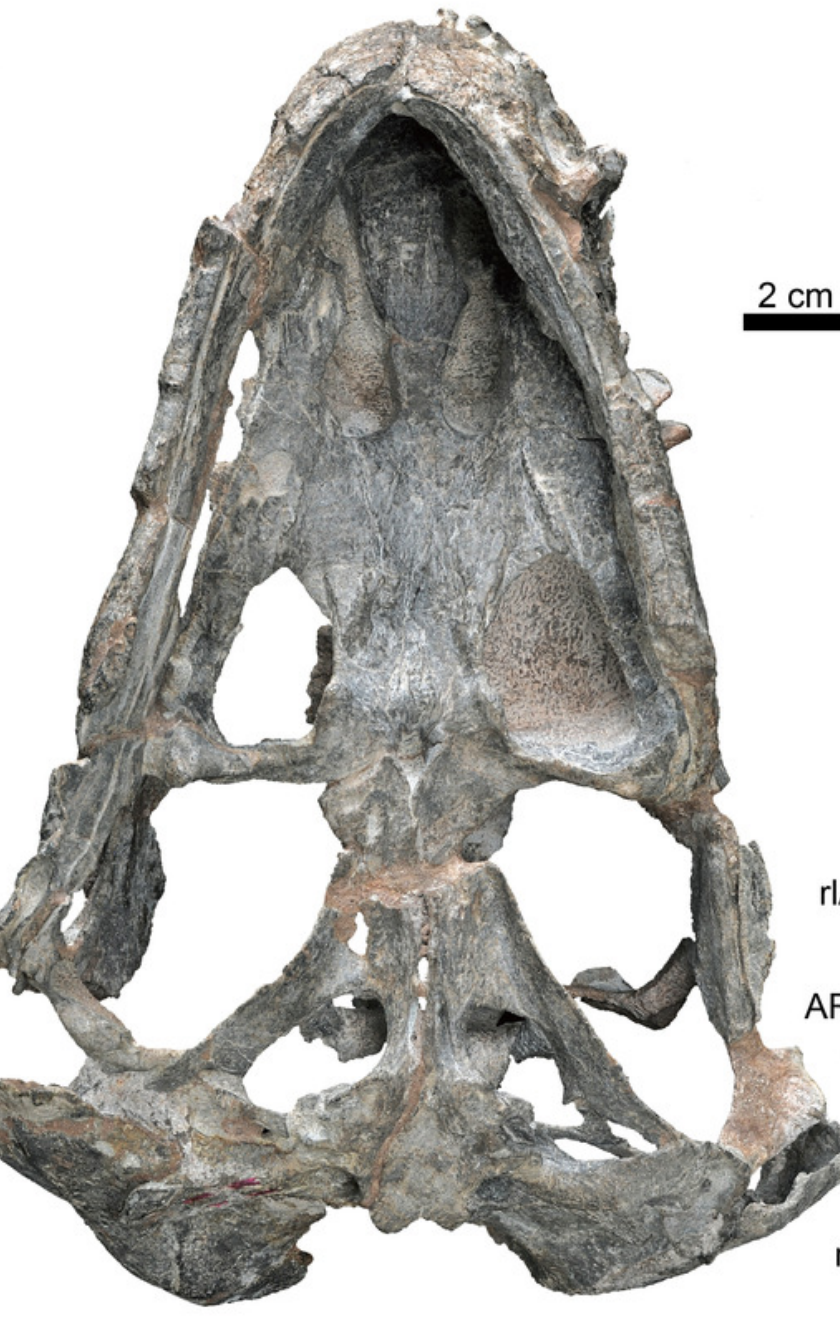

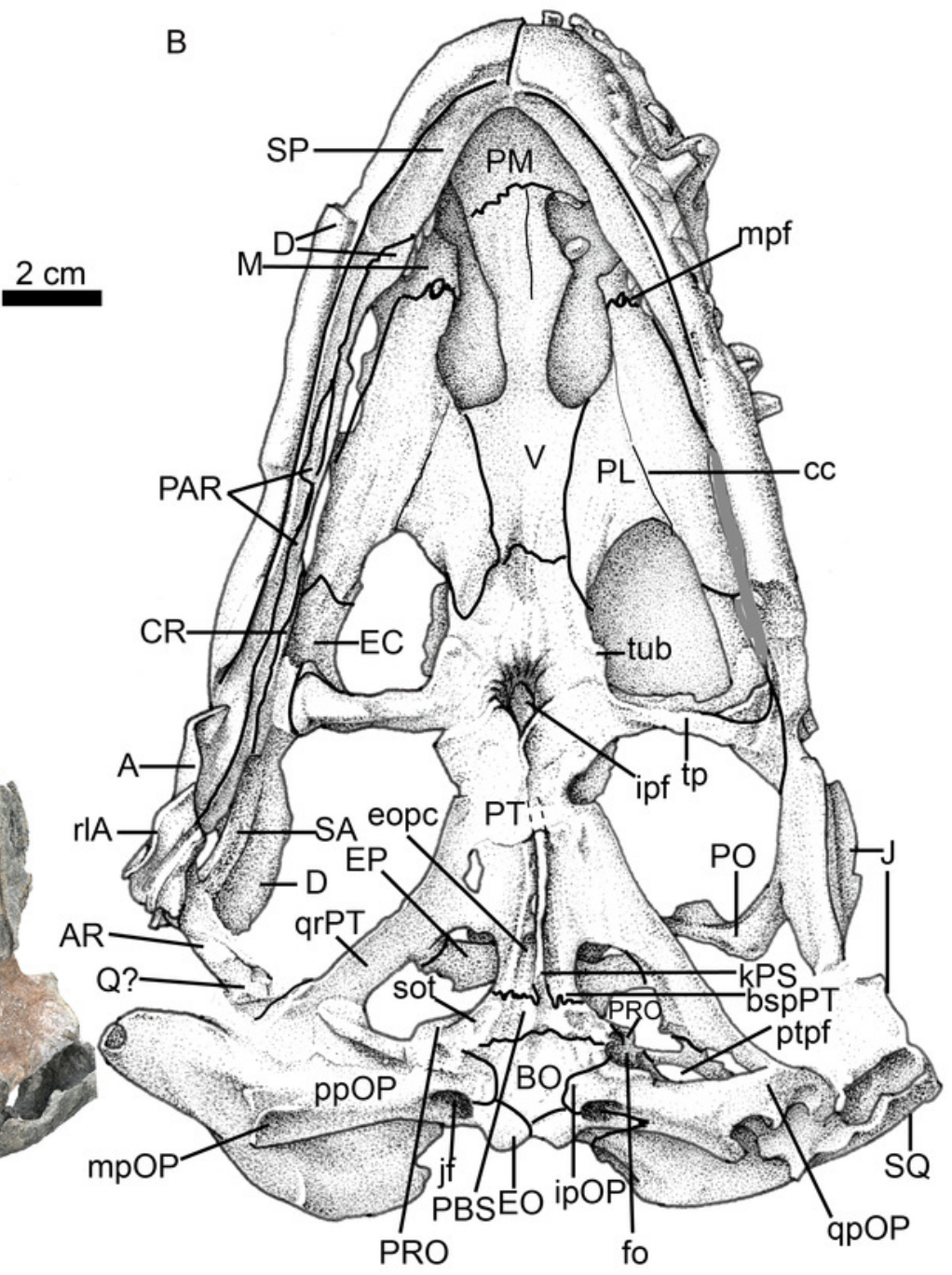




\section{Figure 4}

Holotype of Jiufengia jiai (IVPP V 23877) from the Naobaogou Formation of China. Photo (A) and line drawing $(B)$ of the skull in dorsal view.

Abbreviations: avpSQ: anteroventral process of the squamosal; EP, epiptyerygoid; $F$, frontal; f, foramen; J, jugal; L, lacrimal; M, maxilla; N, nasal; P, parietal; PF, prefrontal; PM, premaxilla; PO, postorbital; pfo, paroccipital fossa; ptpf, pterygo-paroccipital foramen; pvpPRO, posteroventral process of the prootic; Q, quadrate; SM, septomaxilla; SQ, squamosal. Photo credit: Wei Gao. Drawing credit: Yong Xu and Jun Liu.

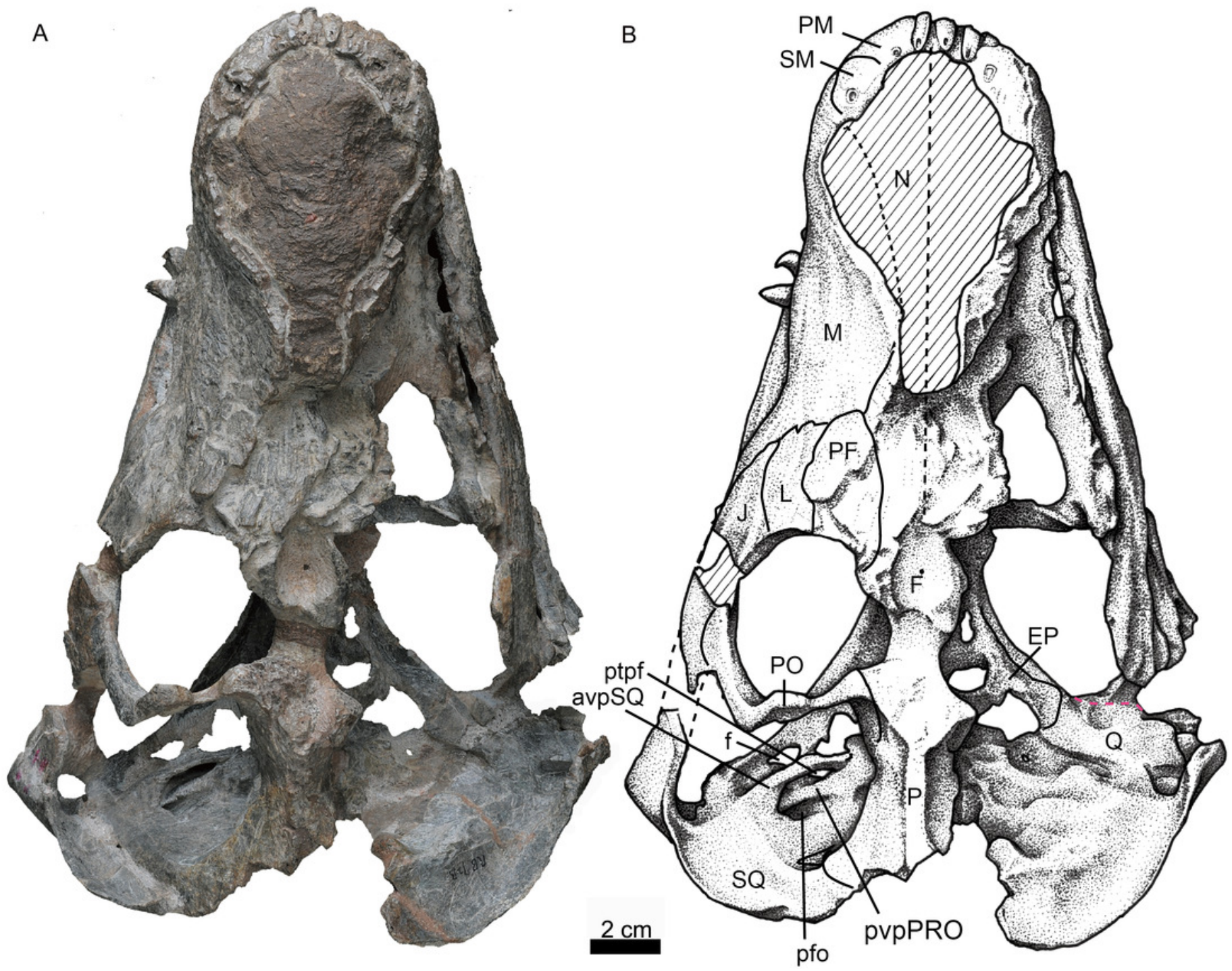




\section{Figure 5}

Holotype of Jiufengia jiai (IVPP V 23877) from the Naobaogou Formation of China. Photo (A) and line drawing (B) of the braincase in left lateral view.

Abbreviations: aelP, anterior extension of the interparietal; avpSQ: anteroventral process of the squamosal; doppf, dorsal opening of the paroccipital fossa; dpSQ, dorsal process of the squamosal; dvf, dorsal venous foramen; E, exoccipital; EP, epipterygoid; F, frontal; Isfo, lateral supraoccipital fossa; OP, opisthotic; P, parietal; pdpPRO, posterodorsal process of the prootic; pfEP, posterior foramen of the epipterygoid; pfo, paroccipital fossa; PO, postorbital; PRO, prootic; PT, pterygoid; ptf, post-temporal fenestra; qrOP, quadrate process of the opisthotic; qrPT, quadrate process of the pterygoid; SO, supraoccipital; SQ, squamosal. Photo credit: Wei Gao. Drawing credit: Yong Xu and Jun Liu.

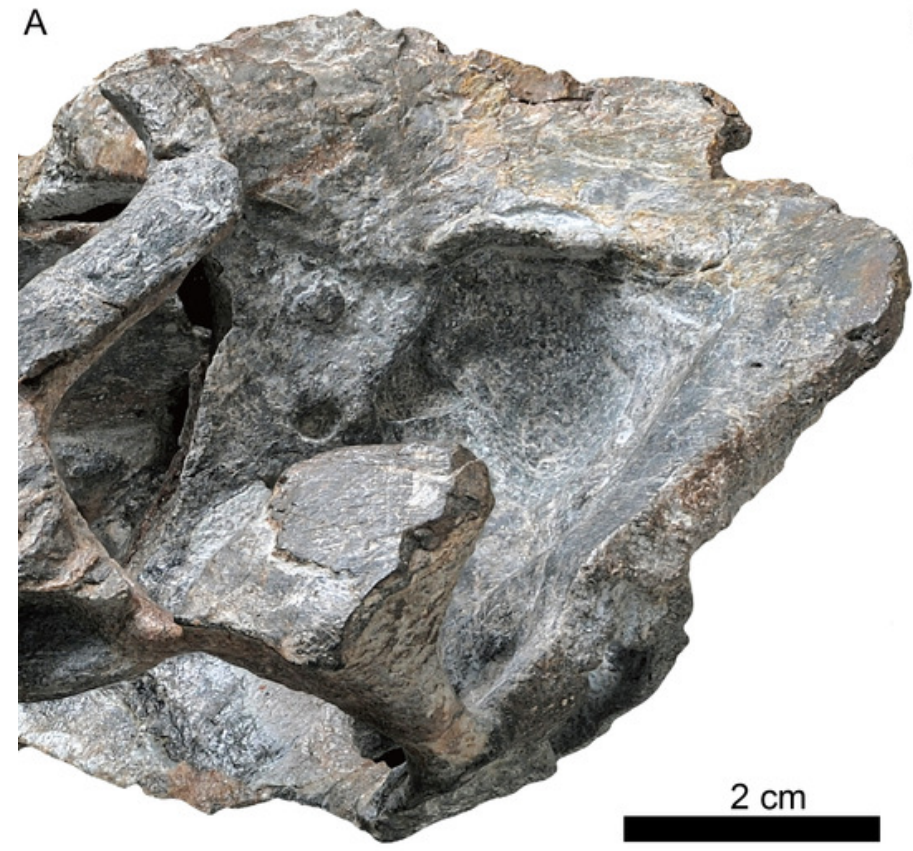

B

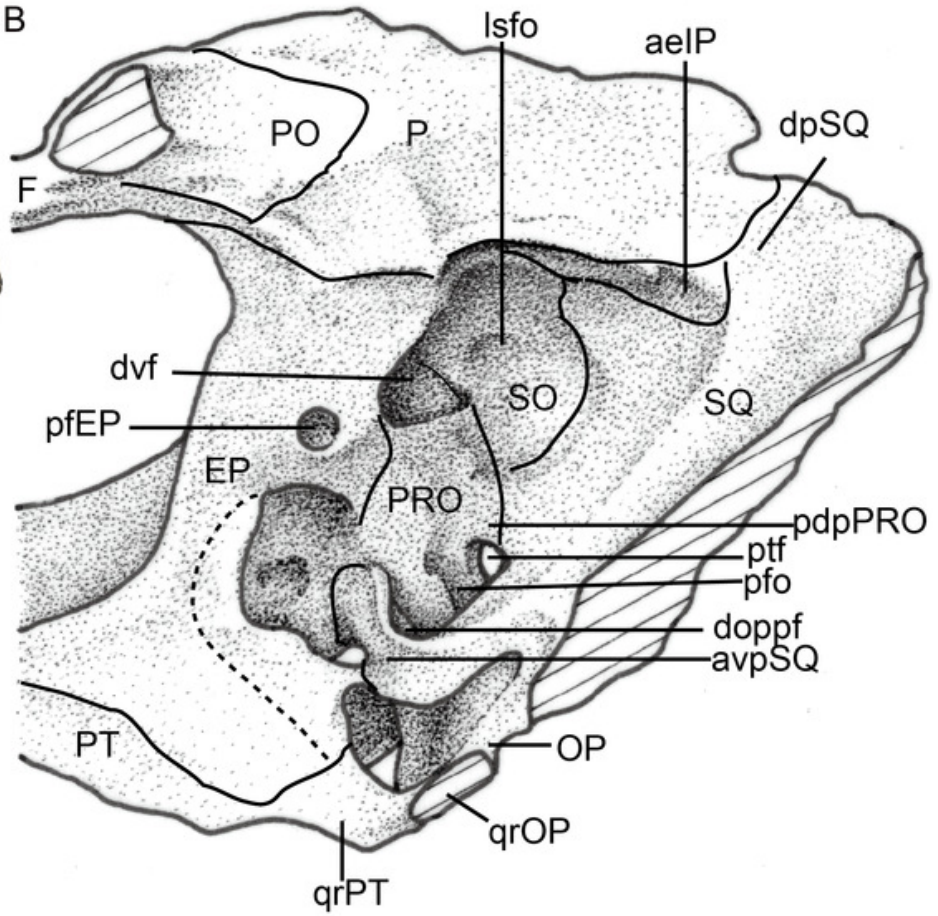




\section{Figure 6}

Holotype of Jiufengia jiai (IVPP V 23877) from the Naobaogou Formation of China. Photo $(A)$ and line drawing $(B)$ of the skull in occipital view.

Abbreviations: EO, exoccipital; fm, foramen magnum; IP, interparietal; jf, jugular foramen; mpOP, mastoid process of the opisthotic; $P$, parietal; pdpOP, posterodorsal process of the opisthotic; ppOP, paroccipital process of the opisthotic; pvpPRO, posteroventral process of the prootic; qpOP, quadrate process of the opisthotic; SO, supraoccipital; SQ, squamosal; T, tabular. Photo credit: Wei Gao. Drawing credit: Yong Xu and Jun Liu.

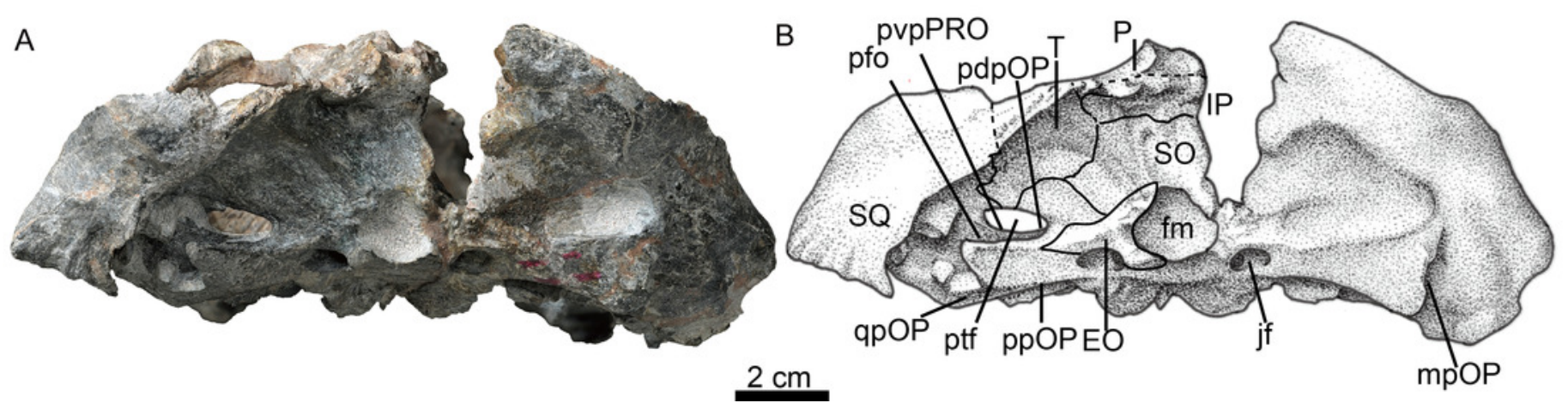




\section{Figure 7}

Holotype of Jiufengia jiai (IVPP V 23877) from the Naobaogou Formation of China. Photo $(A)$ and line drawing $(B)$ of the right mandible in lateral view.

Abbreviations: $A$, angular; $\mathrm{D}$, dentary; $\mathrm{mf}$, mandibular fenestra; pdf, postdentary fossa; rlA, reflected lamina of the angular; SA, surangular. Photo credit: Wei Gao. Drawing credit: Yong Xu and Jun Liu.

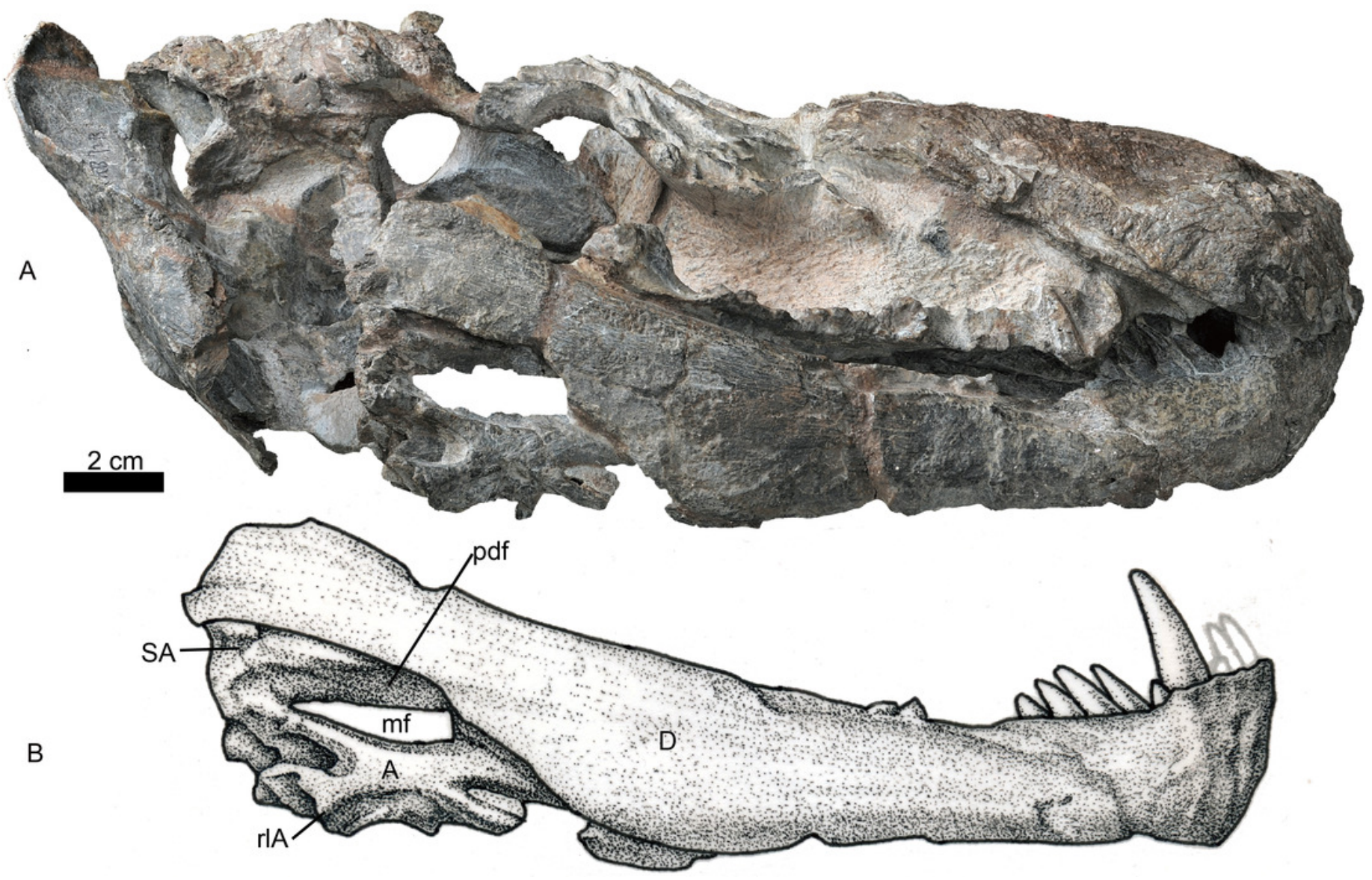




\section{Figure 8}

Holotype of Jiufengia jiai (IVPP V 23877) from the Naobaogou Formation of China. Photos of the postcranial bones.

A, medial view of partial right scapula; B, lateral and C, medial views of right coracoid with small piece of procoracoid; $D$, dorsal and $E$, ventral views of right humerus; $F$, lateral and $G$, medial views of right ulna; $\mathrm{H}$, lateral and I, medial views of right radius. Abbreviations: $c(s c)$, coracoid articular surface for the scapula; dp.cr, deltopectoral crest; ent, entepicondyle; ent $f$, entepicondyle foramen; $f e$, fossa for extensor muscle origin; $f u$, facet for articulation with ulna; $\mathrm{g}(\mathrm{c})$, coracoid part of glenoid fossa; o cart, osseous base from which a presumably cartilaginous olecranon process arose; $\mathrm{pr}$ ar f, proximal articular facet; pv ri, posteroventral ridge; $r$, ridge; subc, fossa for subcracoideus; tub, tuberosity for origin of coracoid head of triceps. Scale bars equal $1 \mathrm{~cm}$. Photo credit: Jun Liu. 

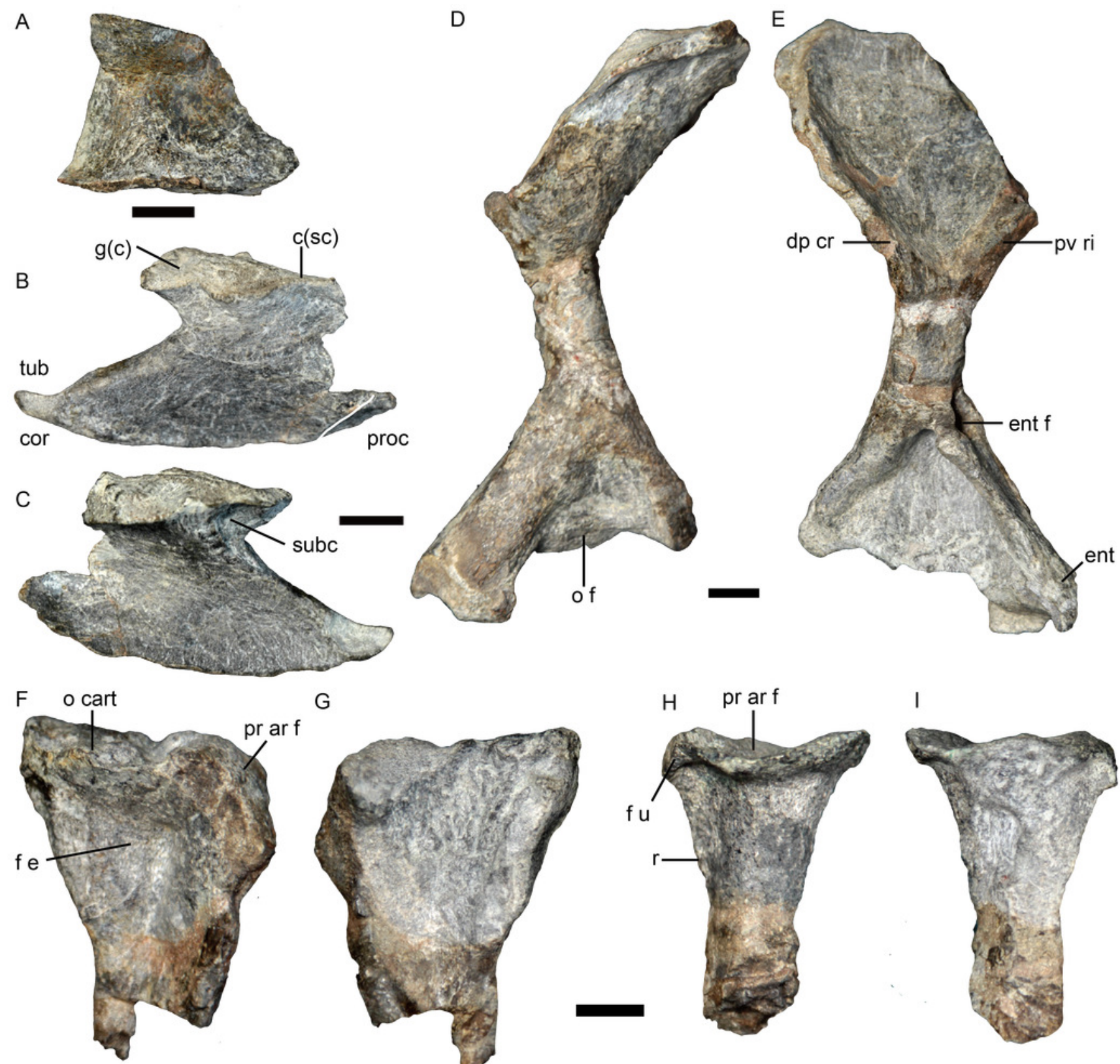

G
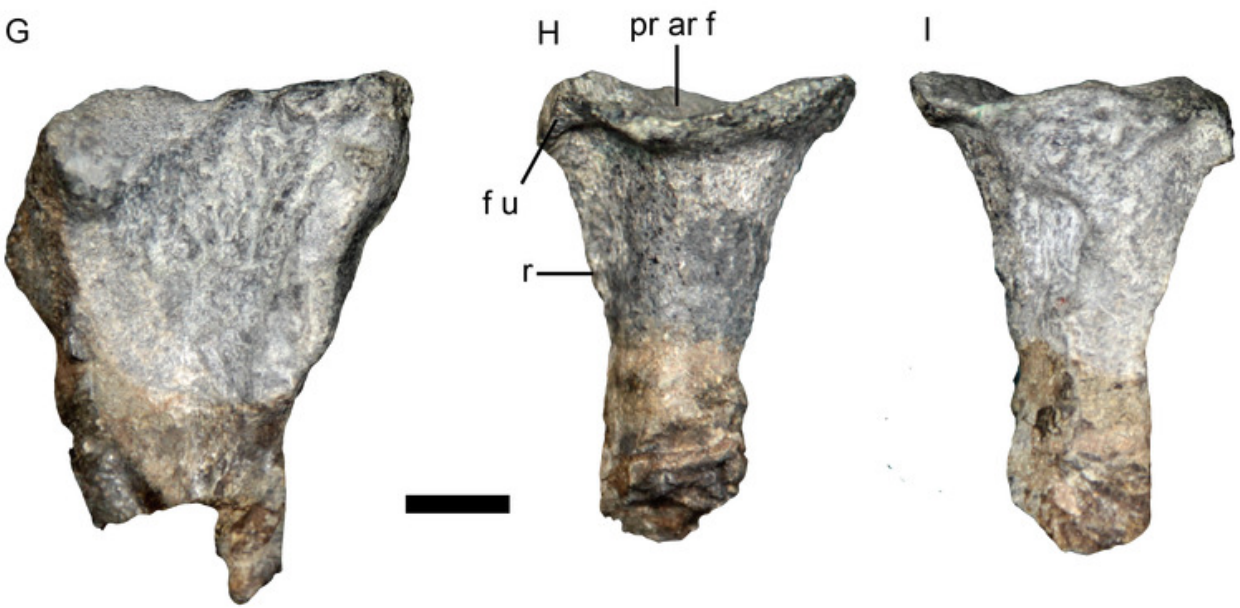


\section{Figure 9}

Holotype of Jiufengnathus jiai (IVPP V 23877) from the Naobaogou Formation of China. The right manus in $A$, dorsal and $B$, ventral views; three phalanges of digit IV in $C$, dorsal and $D$, ventral views.

Abbreviations: d1, distal carpal 1; d2, distal carpal 2; d ph, distal phalange; m1-4, metacarpal 1-4; p ph, proximal phalange; t ph, terminal phalange. Photo credit: Jun Liu.
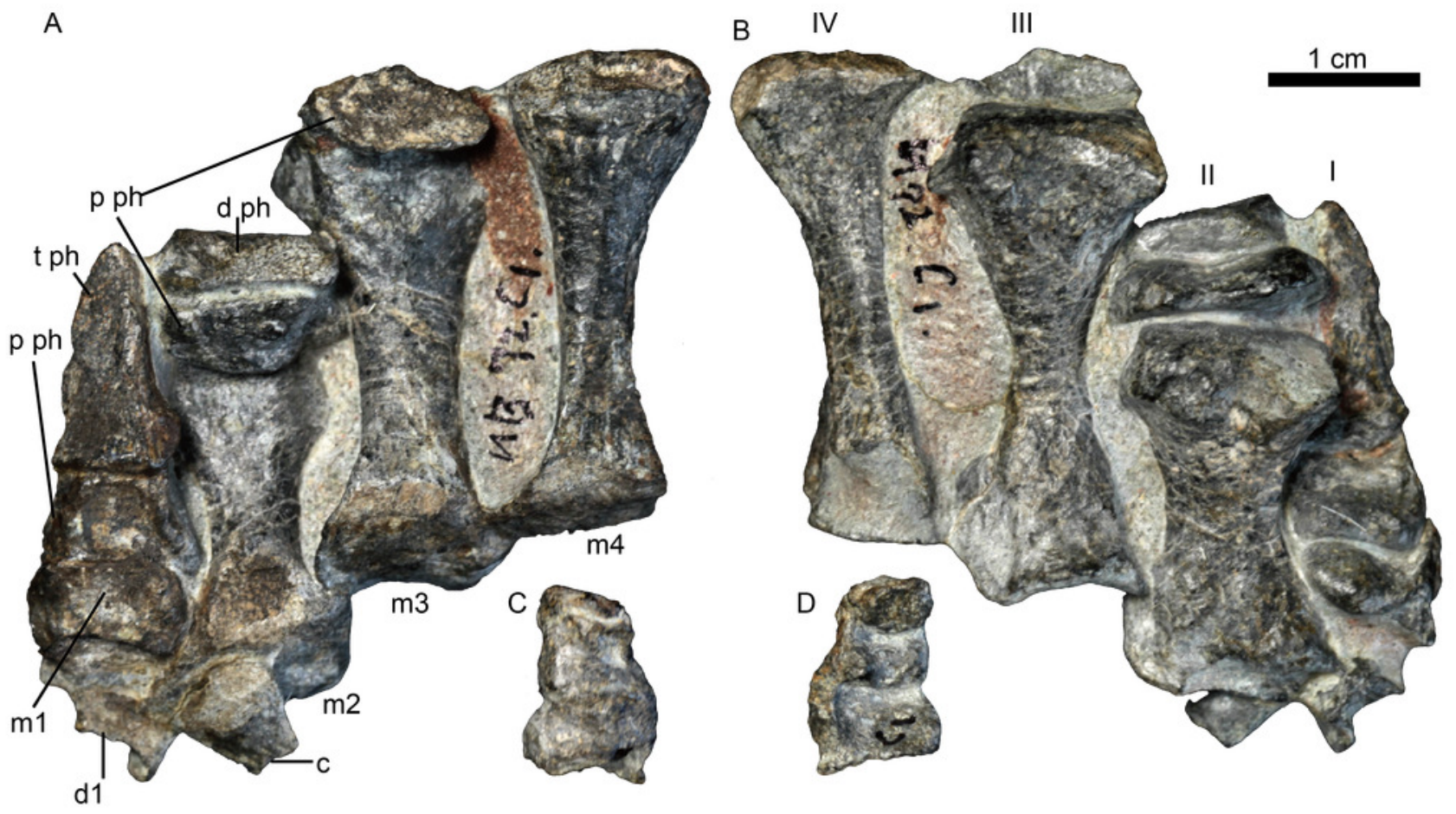


\section{Figure 10}

Majority consensus trees of Therocephalia relationships.

Jiufengia jiai is indicated in red. Numbers below the branch indicates frequency of clades in the fundamental trees; numbers above the branch indicate Bremer support of the groups (only values of 2 or more are indicated). 


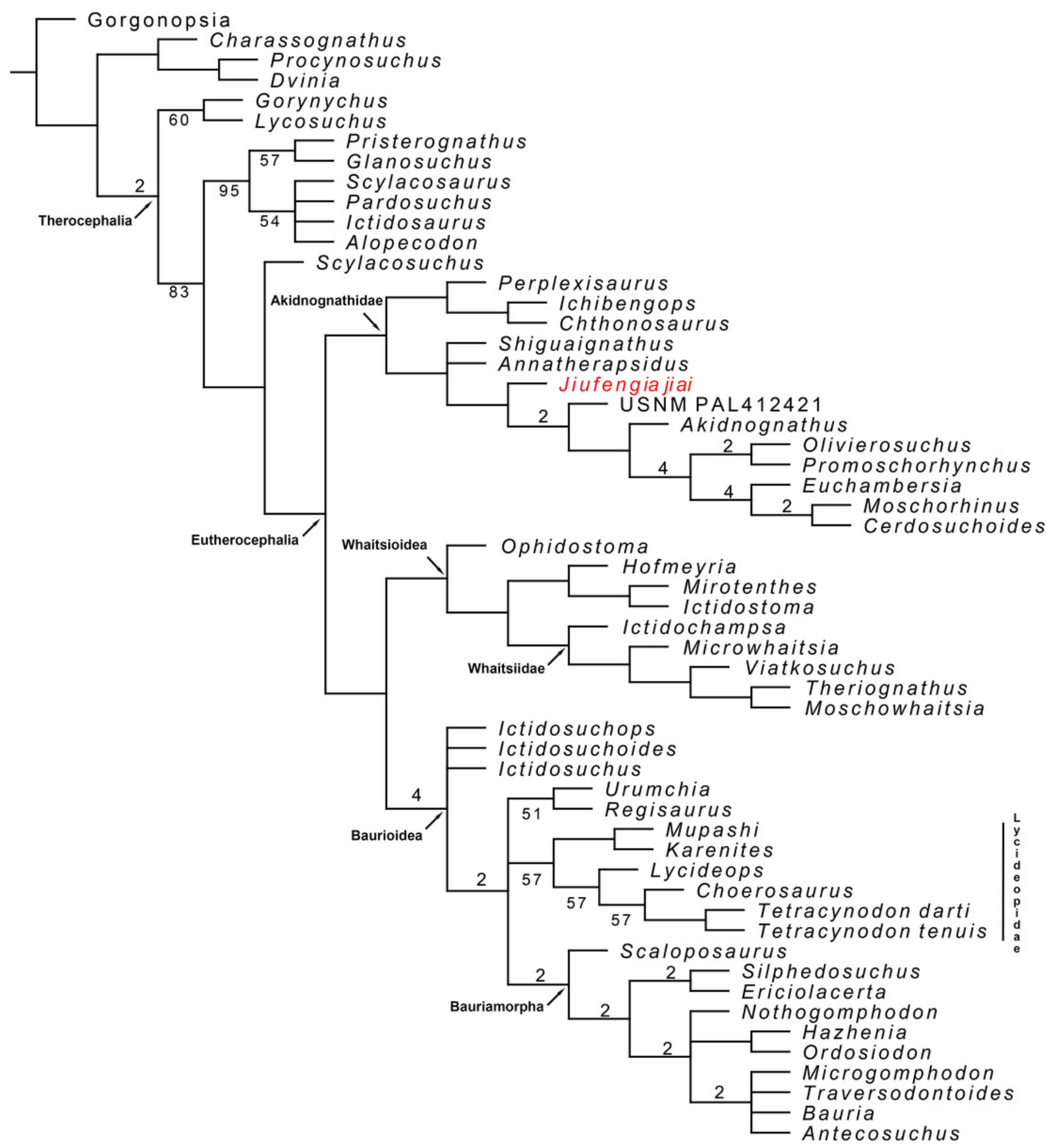




\section{Table $\mathbf{1}$ (on next page)}

Measurements of IVPP V 23877 (in mm). 
1 Table 1 Measurements of IVPPV 23877 (in mm)

2

Dorsal skull length, from tip of the snout to posterior margin of squamosal/occiput $\quad 250$

Basal skull length from tip of the snout to occipital condyle 225

Maximum skull width $\quad \sim 170$

Snout (preorbital) length (left side) $\quad 145$

Length from tip of the snout to anterior border of temporal fenestra 186

$\begin{array}{lc}\text { Breadth of rostrum at level of canines } & 68\end{array}$

$\begin{array}{ll}\text { Length of maxillary dentition } & 60\end{array}$

Total length of upper postcanine tooth row $\quad 32$

3 
Table 2 (on next page)

Teeth count and skull length of akidnognathid specimens. 
1 Table 2 Teeth count and skull length of akidnognathid specimens

2

\begin{tabular}{|c|c|c|c|c|c|c|}
\hline & Incisors & Precanines & Canine & Postcanines & Specimen & Max skull length \\
\hline $\begin{array}{l}\text { Promoschorhynchu } \\
\text { s }\end{array}$ & 5 & 1 & 1 & 5 & $\mathrm{BP} / 1 / 484$ & \\
\hline $\begin{array}{l}\text { Promoschorhynchu } \\
s\end{array}$ & 5 & 2 & 1 & 5 & SAM-PK-K10014 & $123 \mathrm{~mm}$ \\
\hline $\begin{array}{l}\text { Promoschorhynchu } \\
\text { s }\end{array}$ & 5 & 1 & 1 & 5 & RC 116 & $\sim 135 \mathrm{~mm}$ \\
\hline Olivierosuchus & 5 & 2,1 & 1 & 3 & $\mathrm{BP} / 1 / 3849$ & $102 \mathrm{~mm}$ \\
\hline Moschorhinus & 5 & 1 & 1 & 3 & NHMUK R5698 & \\
\hline Moschorhinus & 5 & & 1 & $?$ & $\mathrm{BP} / 1 / 1713$ & $262 \mathrm{~mm}$ \\
\hline Annatherapsidus & 5 & $2 ?$ & 1 & 6 & Ivakhnenko 2011 & $>200 \mathrm{~mm}$ \\
\hline Akidnognathus & 5 & 1 & 1 & 7 & Brink 1961 & \\
\hline Akidnognathus & 5 & 1 & 1 & $? 7$ & SAM-PK-4021 & $107 \mathrm{~mm}$ \\
\hline Euchambersia & 5 & & 1 & & $\mathrm{BP} / 1 / 4009$ & $120 \mathrm{~mm}$ \\
\hline Shiguignathus & 5 & & 1 & 8 & IVPP V 23297 & \\
\hline Jiufengia & 5 & 2 & 1 & 4 & IVPP V 23877 & $250 \mathrm{~mm}$ \\
\hline
\end{tabular}

3 